\title{
Rhizobium etli Mutant Modulates Carbon and Nitrogen Metabolism in Phaseolus vulgaris Nodules
}

\author{
Sonia Silvente, Lourdes Blanco, Alberto Camas, José-Luis Ortega, Mario Ramírez, and \\ Miguel Lara-Flores \\ Centro de Investigación sobre Fijación de Nitrógeno, Universidad Nacional Autónoma de México, Apartado Postal 565-A, \\ Cuernavaca, Morelos, México
}

Submitted 14 January 2002. Accepted 22 March 2002.

\begin{abstract}
The aim of this study was to evaluate the biochemical events in root nodules which lead to increased yield when bean is inoculated with a Rhizobium etli mutant (CFN037) having increased respiratory capacity. CFN037-inoculated plants had $22 \%$ more nitrogen (N) than did wild-type (CE3)-inoculated plants. Root nodule enzymes involved in nodule carbon and nitrogen assimilation as well as in ureides and amides synthesis were assessed in plants inoculated with CFN037 and the CE3. Our results show that the xylem ureides content was lower while that of amino acids was higher in CFN037- compared with CE3-inoculated plants. Supporting these results, enzymes involved in ureide synthesis were reduced while activity of aspartate aminotransferase, glutamate synthase, sucrose synthase, and glucose-6-P dehydrogenase were increased in CFN037induced nodules. Glutamate synthase and phosphoenolpyruvate carboxylase transcripts were detected early in the development of nodules induced by CFN037 compared with CE3. However, plants inoculated with strain CE3-vhb, which express the Vitreoscilla sp. hemoglobin and also displays increased respiratory capacity, did not have altered ureide transport in $\mathrm{N}_{2}$-fixing plants. The data suggest that inoculation with special selected mutant strains of $R$. etli can modulate nodule $\mathrm{N}$ assimilation and $\mathrm{N}$ transport compounds.
\end{abstract}

Symbiotically reduced nitrogen $(\mathrm{N})$ in legume root nodules is assimilated via the incorporation of $\mathrm{NH}_{4}{ }^{+}$into the amide position of glutamine in a reaction catalyzed by glutamine synthetase (GS) (EC 6.3.1.2). GS catalyzes the ATP-dependent condensation of $\mathrm{NH}_{3}{ }^{+}$with glutamate to produce glutamine. Subsequently, glutamate synthase, (NADH-GOGAT) (EC 1.4.1.14) transfers the amido group of glutamine to $\alpha$ ketoglutarate, producing two molecules of glutamate. These two reactions, collectively referred to as the GS/GOGAT cycle, are now generally agreed to be the primary route of entry for nitrogen in whole-plant metabolism. In $\mathrm{N}_{2}$-fixing legume nodules, NADH-GOGAT activity has been found to increase markedly during nodule development, and this activity is associated with a single form of this enzyme in alfalfa (Gregerson et al. 1993). In bean nodules, NADH-GOGAT appears to occur as two isoforms (Chen and Cullimore

Corresponding author: M. Lara-Flores, Telephone: 52777329 1815; Fax: 52777317 5581; E-mail lara@cifn.unam.mx.

Current address of J.-L. Ortega: New Mexico State University, Plant Genetic Engineering Laboratory, Box 3GL, Las Cruces 88003.
1988). In temperate legumes, the assimilated nitrogen is transported from the nodules to the shoot in the form of amides (glutamine and asparagine), whereas nodules of tropical legumes export ureides (allantoin and allantoic acid). Ureides are produced by de novo synthesis of purine nucleotides in infected cells followed by degradation to ureide in uninfected cells (Atkins 1982; Atkins et al. 1991). Accordingly, synthesis of purine nucleotides is highly induced in nodules following commencement of nitrogen fixation. Moreover, enzymes of purine degradation are present in plant nodules (Schubert 1986). Xanthine dehydrogenase and uricase are important enzymes of the purine degradation pathway. They sequentially catalyze the oxidation of hypoxanthine and xanthine to uric acid, and the oxidative breakdown of uric acid to yield allantoin. The allantoin then is transformed to allantoic acid by the enzyme allantoinase. Ureides comprise 70 to $95 \%$ of total organic nitrogen in the xylem sap when bean plants are growing symbiotically with $\mathrm{N}_{2}$-fixing microorganisms. It has been proposed that the abundance of ureides in the plant shoot axis reflects the symbiotic dependence of the plant and provide a quantitative assay of $\mathrm{N}_{2}$ fixation (Herridge 1982; McClure and Israel 1979).

Photosynthesis provides the carbon needed to generate energy for $\mathrm{N}_{2}$ reduction and for ammonia assimilation. Sucrose is first cleaved by sucrose synthase (SS) (EC 2.4.1.13) in mature nodules to produce UDP-glucose and fructose which, after phosphorylation by hexokinases, enter the glycolytic or oxidative pentose phosphate pathways (OPPP) and are metabolized to phosphoenolpyruvate (PEP). It has been postulated that the OPPP may have a more important role in the carbon metabolism of ureide-exporting nodules than in amide exporters (Hong and Copeland 1990). This pathway provides a source of ribose-5-phosphate, required for ureide synthesis. Glucose-6P-dehydrogenase $(\mathrm{G} 6 \mathrm{PDH})$, which catalyzes the first reaction of the OPPP, represents a strategic control point in the pathway. Phosphoenolpyruvate carboxylase (PEPc) (EC 4.1.1.31), which carboxylates PEP, is of primary importance for the carbon metabolism in symbiotic nodules of legume roots where it reassimilates a substantial amount of the $\mathrm{CO}_{2}$ respired by nodules, supplies dicarboxylates that supports respiration of bacteroids, and supplies the carbon skeleton for the synthesis of amides and ureides for the translocation of fixed nitrogen (Deroche and Carrayol 1988; Tajima and Kouchi 1996). It is estimated that up to $25 \%$ of the carbon required for energy to support nitrogenase activity and ammonia assimilation may be supplied by PEPc (King et al. 1986).

Symbiotic nitrogen fixation by Rhizobium spp. is an energyconsuming process, requiring at least 16 ATP molecules to reduce one molecule of $\mathrm{N}_{2}$. 
Bacterial respiration, which depends of the carbon supplied from the plant, fulfills the ATP required for nitrogen fixation. $R$. etli mutants having increased respiratory capacity and improved symbiotic nitrogen fixation have been isolated (Miranda et al. 1996; Soberón et al. 1989, 1990). One such mutant, $R$. etli CFN037, showed twofold higher acetylene reduction activity than CE3-inoculated plants at day 19 after inoculation, and plants inoculated with this mutant had $22 \%$ more nitrogen than did wild-type inoculated plants (Soberón et al. 1990). Cytochrome spectral analysis and expression of the fixNOQP operon in the stationary phase of growth revealed that $R$ etli mutant $\mathrm{CFN} 037$ produced the symbiotic cytochrome terminal oxidase $c b b_{3}$, which is not seen in the wild-type strain under such conditions. The Tn5mob insertion in CFN037 occurred in the promoter region of the thiCOGE gene cluster (involved in the synthesis of thiamine) and promotes constitutive expression of thiC gene, because it is not repressed by thiamine as in the CE3 strain (Miranda et al. 1997). Another R. etli strain, CE3-vhb (originally named CE3/pMR4), has been engineered for the expression of the Vitreoscilla sp. hemoglobin, which stimulated the respiratory efficiency of free-living rhizobia under most limiting oxygen concentrations, and most probably of symbiotic bacteroids, because plants inoculated with this strain exhibited higher levels of symbiotic nitrogen fixation and total nitrogen content (Ramirez et al. 1999).

In this article, we explore whether inoculation of bean with a $R$. etli mutant having increased respiratory capacity affects plant $\mathrm{N}$ and $\mathrm{C}$ metabolism. Enzymes involved in the synthesis of ureides and amides as well as in the ammonia and carbon assimilation pathway were analyzed in nodules, induced by the $R$. etli wild-type strain CE3 and its derivative strain, CFN037. We show that $\mathrm{N}_{2}$-fixing plants inoculated with the Rhizobium mutant CFN037 had reduced synthesis and transport of ureides with concomitantly increased amide metabolism.

\section{RESULTS}

\section{Ureide and amino acid content in the xylem sap.}

Ureide concentration in xylem exudate of nitrogen-fixing plants was measured from day 11 to day 21 after inoculation (Fig. 1). From day 15 to day 21, ureide content in the xylem of plants inoculated with the Rhizobium strain CE3 was consistently higher than in the xylem of the plants inoculated with the Rhizobium mutant CFN037. By day 21, ureide concentration in the xylem sap of CE3-inoculated plants was twofold greater than that of CFN037-inoculated plants (Fig. 1). By comparison, the concentration of Gln, Asn/Ser, Glu, and most other amino acids tested were two- to threefold higher in the xylem sap of CFN037-inoculated than in xylem sap of CE3-inoculated plants at day 11 and 18 after inoculation (Fig. 2). By day 18, Asn/Ser, Gln, and Glu concentration was almost 4, 2, and 2.5 times higher, respectively, in CFN037- than in CE3-inoculated plants. These results indicated that plants inoculated with the Rhizobium respiratory mutant CFN037 had reduced ureide transport while amide transport was increased compared with plants inoculated with the wild-type strain CE3.

\section{Regulation of nodule enzymes.}

Ureide synthesis. In order to explain the different levels of ureides detected in the xylem sap of bean plants, the activities of nodule xanthine dehydrogenase $(\mathrm{XDH})$, uricase, and allantoinase were determined throughout nodule development (Fig. 1). From day 13 to $21, \mathrm{XDH}$ activity in CE3-induced nodules was $40 \%$ (as day 13) to $30 \%$ higher than in nodules inoculated with the Rhizobium mutant CFN037 (Fig. 1). Allantoinase activity in nodules inoculated with the Rhizobium strain CE3 was sixfold greater than in CFN037-induced nodules by day 11 (Fig. 1). In contrast, CFN037 nodules displayed a sharp increase in allantoinase activity up to day 15 , after which allantoinase activity was markedly reduced, declining to $50 \%$ by day 21 after inoculation (Fig. 1). Uricase activity was similar in both CE3- and CFN037-induced nodules (Fig. 1). The higher activity of $\mathrm{XDH}$ and allantoinase in CE3 nodules possibly could explain the higher amount of ureide detected in the xylem of CE3-inoculated plants.

Carbon metabolism. In agreement with the proposed role of G6PDH in the synthesis of ureides, our results showed a positive correlation between nodule G6PDH activity and the ureides content in the xylem (Fig. 1). During the period analyzed, G6PDH activity was consistently high in nodules inoculated with the Rhizobium wild-type strain CE3. After the onset of $\mathrm{N}_{2}$-fixation (day 12), G6PDH activity was higher in CE3- than in CFN037-induced nodules. CFN037-induced

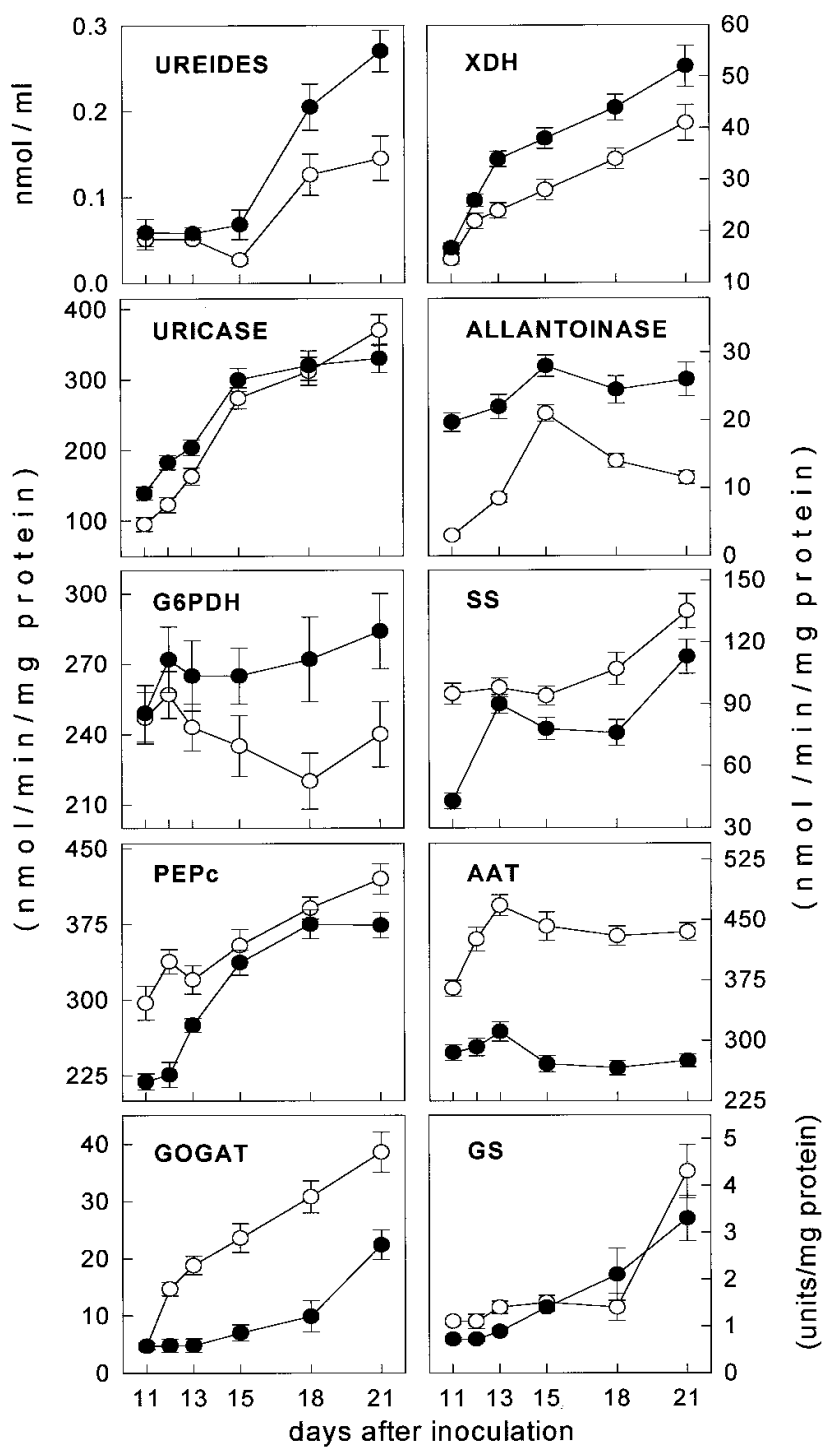

Fig. 1. Nodule enzyme activities and levels of ureide in the xylem sap of nitrogen-fixing plants, inoculated with the Rhizobium wild-type strains CE3 (-) and the respiratory mutant CFN037 (O). Ureides levels, xanthine dehydrogenase (XDH), uricase, allantoinase, glucose 6-Pdehydrogenase (G6PDH), sucrose synthase (SS), posphoenolpyruvate carboxilase (PEPc), aspartato aminotransferase (AAT), glutamato synthase (NADH-GOGAT), and glutamine synthetase (GS) activities were determined at different days after inoculation. In all, 10 to 15 plants were analyzed per sample. Values are means \pm standard error $(n=5)$. 
nodules presented a slight reduction in G6PDH activity from day 12 to 21 (Fig. 1).

Nodules induced by the $R$. etli mutant CFN037 exhibited higher PEPc activity, at early stages of nodule development (11 to 12 days) than CE3-induced nodules. From day 13 after inoculation, no significant differences in PEPc activity between both types of nodules was observed (Fig. 1). SS activity was slightly higher in CFN037 than in CE3 nodules from day 15 to day 21 after inoculation. However, similarly to PEPc, SS activity was significantly higher at day 11 in CFN037- than in CE3-induced nodules. The higher PEPc activity observed in early stages of CFN037-induced nodules is in accordance with the high PEPc transcript levels detected from day 11 to 15 (Fig. 3). In contrast, the high SS activity at day 11 in CFN037 nodules is not in accordance with the very similar SS mRNA levels detected in both types of nodules at early stages of development (Fig. 3).

\section{Ammonia assimilation.}

The activities of GS, NADH-GOGAT, and aspartate aminotransferase (AAT) were measured during the development of nodules induced by the CE3 and CFN037 $R$. etli strains (Fig. 1). GS activity as well as GS mRNA levels increase gradually in both CFN037 and CE3 nodules, but no differences in either GS activity or GS transcript levels were detected between these two type of nodules (Figs. 1 and 3), supporting the previous observation that there is a poor correlation between GS activity and bacterial respiration (Ortega et al. 1992).

The main correlation between Rhizobium sp. respiration and enhanced ammonia assimilation pathway was observed in the activity of NADH-GOGAT (Fig. 1). R. etli mutant CFN037 promoted a high level of nodule NADH-GOGAT activity, which is threefold greater than the activity found in nodules induced by the $R$. etli strain CE3, during most of the period analyzed.

NADH-GOGAT is postulated to be the rate limiting step in nodule $\mathrm{N}$ assimilation in alfalfa and pea (Benny and Boland 1977; Gregerson et al. 1993), where only a single form of the

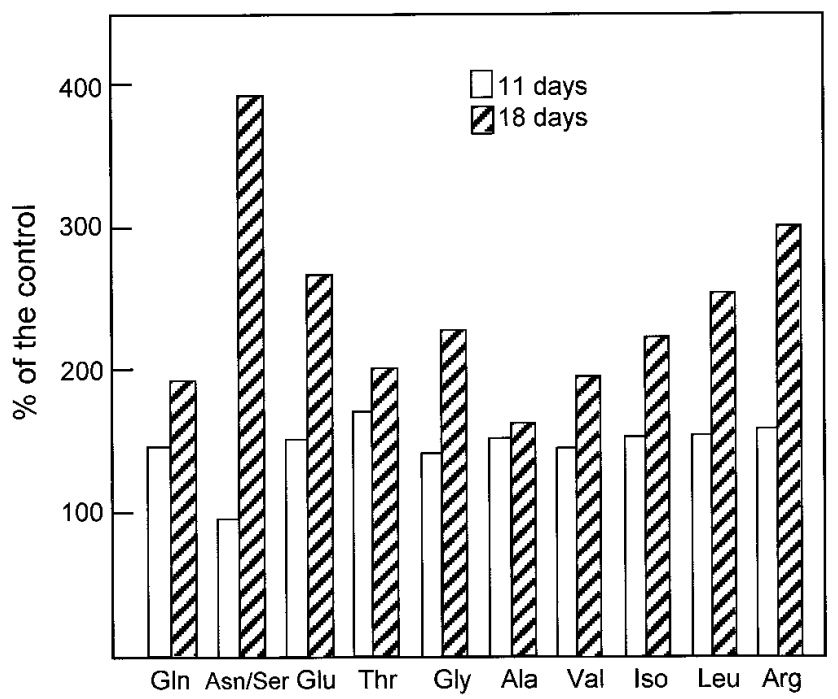

Fig. 2. Amino acid composition of xylem sap from plants inoculated with the Rhizobium etli mutant CFN037. Amino acid concentration is reported as percentage of the amino acid content found in the xylem of plants inoculated with the $R$. etli strain CE3 (control). Xylem sap samples were collected at 11 and 18 days after inoculation. The amino acid concentration $(\mu \mathrm{M})$ of the control at (11 and 18 days) were Gln (78.6119.6), Asn/Ser (153.9-24.9), Glu (46-22), Thr (27-23), Gly (9.7-6), Ala (24.4-14.3), Val (59.6-24.6), Iso (44.5-13.4), Leu (34.8-10), and Arg (30.6-23.9). Values are means \pm standard error $(n=3)$. enzyme is found. By comparison, bean has been shown to have two forms of NADH-GOGAT. We have recently isolated two partial NADH-GOGAT cDNAs. In order to analyze the expression of bean NADH-GOGAT isoforms, 3' untranslated region (UTR)-specific fragments for two cDNA clones, PvNADH-GOGAT-4 and PvNADH-GOGAT-15, were used as probes (Fig. 3). Increasing levels of PvNADH-GOGAT-15 transcript were detected in both CE3- or CFN037-induced nodules. CE3-induced nodules displayed the high mRNA levels of PvNADH-GOGAT-15 at days 18 and 21, while CFN037-induced nodules exhibited an early induction of PvNADH-GOGAT-15 (day 11), reaching its maximal level at day 21 after inoculation (Fig. 3). PvNADH-GOGAT-4 was detected in both CE3 and CFN037 nodules but the abundance was much greater in CFN037 nodules. The earliest expression of PvNADH-GOGAT-15 and the predominant expression of PvNADH-GOGAT-4 in CFN037-induced nodules help explain the high activity of this enzyme in this type of nodules.

AAT, a key enzyme for ammonia incorporation into aspartate and asparagine when amides are transported to the shoot (Griffith and Vance 1989), had significantly higher specific activity in CFN037- than in CE3-induced nodules during the period tested (Fig. 1). AAT activity in CFN037 nodules increased from 11 to 13 days and then remained relatively constant to day 21 after inoculation. In CE3-induced nodules, AAT activity remained almost constant throughout the period tested (Fig. 1). The high GOGAT-NADH and AAT activities in CFN037induced nodules are consistent with the increased amino acid content found in the xylem of plants inoculated with this mutant (Fig. 2).

\section{Another respiratory mutant and ureide transport.}

The results obtained suggested the possibility that inoculation of bean with mutants of $R$. etli can modify nodule $\mathrm{N}$ and $\mathrm{C}$ metabolism. To ascertain whether another $R$. etli mutant with increased respiration could influence ureide metabolism, bean was inoculated with $R$. etli CE3-vhb, which expresses the Vitreoscilla sp. hemoglobin (Ramirez et al. 1999). The CE3$v h b$ strain also had increased respiratory efficiency of free-living rhizobia under limiting oxygen concentration and higher nitrogenase activity (Ramirez et al. 1999). In contrast to the results obtained with the CFN037 strain, no difference in the ureide content was detected in the xylem sap of plants inoculated with the wild-type strain CE3 and its derivative engineered strain CE3-vhb (data not shown). Both strains CFN037 and CE3-vhb were selected by their increased respiratory capacity; therefore, these results suggest that modified bacterial respiration per se is not directly related to the synthesis and transport of ureides in $\mathrm{N}_{2}$-fixing bean plants.

\section{DISCUSSION}

\section{Nodule ammonia and carbon assimilation.}

Here, we extended the present understanding of legumerhizobial interaction by showing that it is possible to modify plant $\mathrm{N}$ assimilation by inoculation with a $R$. etli mutant. Surprisingly, we found that the synthesis of ureides can, in part, be shifted to amides by inoculation with a rhizobia strain with increased respiratory capacity (CFN037). In addition, we demonstrated that root nodules have two forms of NADH-GOGAT.

With respect to the ammonia assimilation pathway, the main difference was the threefold higher NADH-GOGAT activity found in CFN037- compared with CE3-induced nodules. As mentioned above, little difference in GS expression was detected between CE3 and CFN037 nodules (Ortega et al. 1992). These results support the idea that GOGAT activity is a key factor in the regulation of ammonia assimilation capacity in 
the nodule. Although the presence of two NADH-GOGAT isoforms has been reported in bean nodules (Chen and Cullimore 1988), no cDNAs were available for these enzymes. Here we report, for the first time, the presence and differential expression of two distinct NADH-GOGAT mRNAs in bean nodules, suggesting that these two NADH-GOGAT isoforms are encoded by two different genes.

The early induction of SS and PEPc activities in nodules induced by the Rhizobium mutant CFN037 suggest an increase in $\mathrm{C}$ metabolism, which is consistent with the high respiratory capacity of the symbiotic bacteroid and with the increased ammonia assimilation activity detected in CFN037 nodules.

Although our results on activity and RNA levels displayed some inconsistency for SS, recently we obtained evidence indicating the expression of two SS genes in bean plants. One of these SS genes is nodule enhanced, the other is expressed in different tissues. We have not been able to establish the extent to which this second SS gene is expressed in nodules. These results could explain the differences in SS activity and the similarities in SS transcript levels observed between CFN037 and CE3 nodules.

\section{Ureides synthesis and transport.}

Our results indicated that, when $R$. etli mutant CFN037 with increased respiration and $\mathrm{N}_{2}$ fixation capacity is inoculated on bean, synthesis and transport of ureides is reduced while the synthesis and transport of amides and other amino acids is enhanced. Concomitant with these results, $\mathrm{XDH}$, allantoinase, and G6PDH activities were lower in CFN037- than in CE3-inoculated plants. Moreover, AAT activity was 20 to $40 \%$ higher in CFN037- than in CE3-induced nodules, providing supporting evidence for the idea that the CFN037 mutant produces fewer ureides and promotes amide synthesis in bean nodules. Previous reports established a correlation between nitrogenase activity and ureide content (Herridge 1982; van Berkum et al. 1985) and indicated that ureides in the plant shoot axis may provide a quantitative analysis of $\mathrm{N}_{2}$ fixation (Herridge 1982; McClure and Israel 1979). The Rhizobium mutant CFN037 is a better nitrogen fixer than the CE3 (Ortega et al. 1992; Soberón et al. 1989); therefore, our results suggest that ureide transport may not always directly reflect the efficiency of $\mathrm{N}_{2}$ fixation. Since bean plants are ureide transporters, our result demonstrated for the first time that a Rhizobium strain can modify plant $\mathrm{N}$ transport and metabolism.

\section{Not all respiratory mutants effect ureide synthesis.}

Two Rhizobium mutants (CFN037 and CE3-vhb) with increased respiratory and nitrogen fixation capacity were used in order to understand whether bacterial respiration affects nodule metabolism. CFN037 but not the CE3-vhb strain reduced the ureide content in the xylem sap of $\mathrm{N}_{2}$-fixing plants. The high respiratory capacity of Rhizobium strain CFN037 is due to a constitutive expression of the thiC gene which is involved in the synthesis of thiamine (Miranda et al. 1997). These results could be explained by considering that thiamine is composed of two moieties: the thiazole moiety, 4-methyl-5-( $\beta$-hydroxyethyl)-thiazole (THZ), and the pyrimidine moiety, 4amino-5-hydroxymethyl-2-methylpyrimidine (HMP). HMP is synthesized from 5-aminoimidazole ribotide (AIR) by the action of thiC gene product (Petersen and Downs 1997; White and Spenser 1996). AIR is also a key intermediate in the synthesis of purine nucleotides and of ureides in root nodules of ureide-transporting legumes. Considering this, the lower synthesis and transport of ureides in CFN037-inoculated plants may be related (through thiC constitutive expression) to draining AIR from the plant fraction, reducing the production of ureides in the nodule. This explanation implies that AIR is transported from the plant fraction to the bacteroid, and also suggests that limited purine synthesis occurs in the bacteroid. This suggestion deserves further attention.

\section{MATERIALS AND METHODS}

Plant material and growth conditions.

Phaseolus vulgaris cv. Negro jamapa seeds (ProNaSe, México DF) were surface sterilized in sodium hypochlorite solution $(20 \%)$ for $10 \mathrm{~min}$ and germinated on moist sterile filter paper. Three-day-old seedlings were transferred to vermiculite-containing pots (five plants per pot) and then inoculated with different $R$. etli strains. Plants were grown in a naturally lighted greenhouse. Pots were watered every 2 days with a nitrogen-free solution (Broughton and Dilworth 1971). Nodules were harvested from 11 to 21 days after inoculation, immediately frozen in liquid nitrogen, and stored at $-70^{\circ} \mathrm{C}$ until use.

\section{Rhizobium strains.}

Rhizobium strains employed were the $R$. etli wild-type strain CE3 (Noel et al. 1984) and its derivative strain CFN037, isolated by its increased capacity to oxidize $N, N, N^{\prime}, N^{\prime}$-tetramethyl-p-phenylenediamine (TMPD) (Soberón et al. 1989, 1990) and the engineered CE3 strain containing the Vitreoscilla sp.

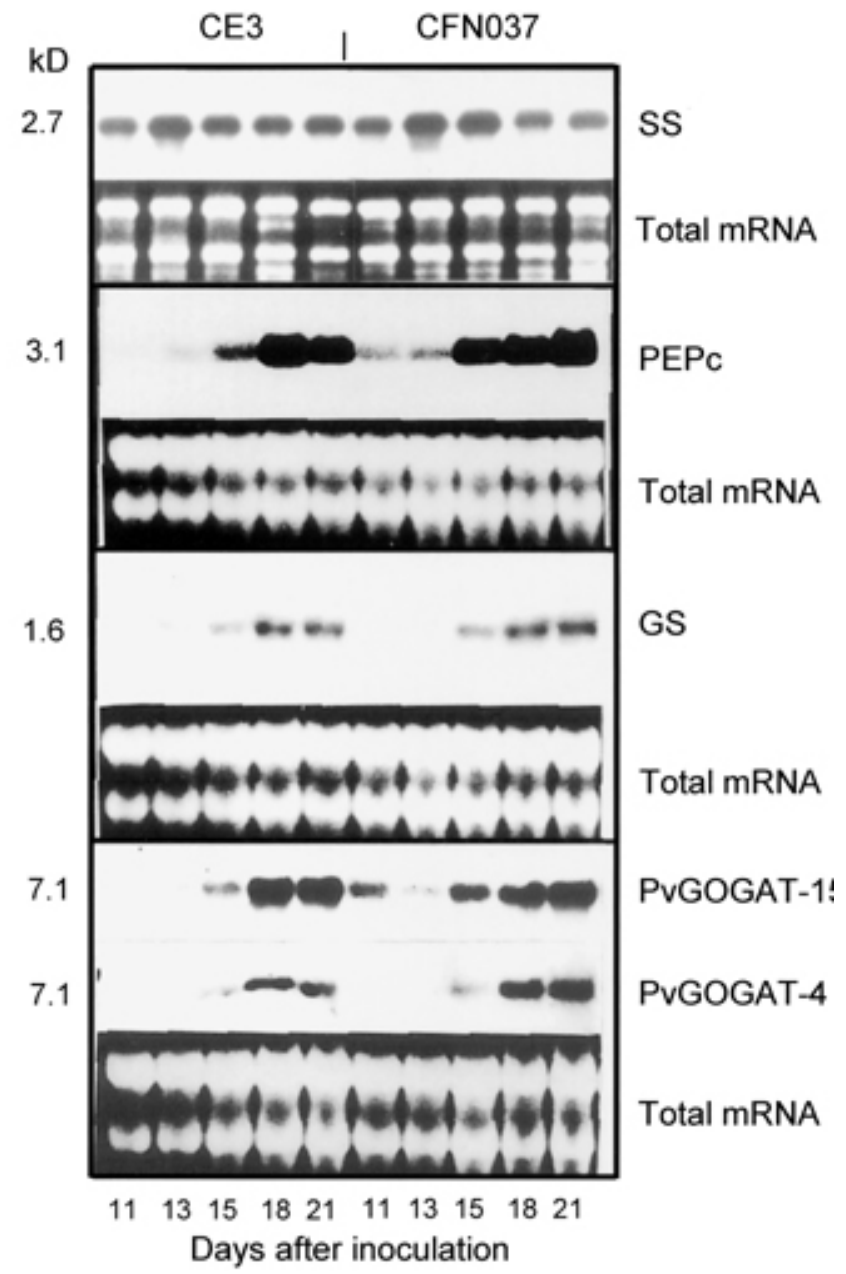

Fig. 3. Expression analysis of sucrose synthase (SS), posphoenolpyruvate carboxilase (PEPc), glutamine synthetase (GS), and glutamato synthase (NADH-GOGAT) in nodules induced by the Rhizobium etli wild-type strain CE3 and the respiratory mutant CFN037 development. Total RNA $(20 \mu \mathrm{g})$ extracted from nodules harvested at different days after inoculation was loaded in each lane. Blots were hybridized with radiolabeled specific probes. 
hemoglobin gene previously named CE3/pMR4 (Ramirez et al. 1999) that will be referred to as CE3-vhb.

\section{Preparation of soluble proteins.}

Nodules from $11,12,13,15,18$, and 21 days after inoculation were ground in a chilled mortar and pestle with $1: 3$ (wt/vol) extraction buffer (50 mM Hepes, $\mathrm{pH} 7.8$, containing 1 $\mathrm{mM}$ EDTA, $20 \%$ [vol/vol] glycerol, $5 \%$ [vol/vol] ethylene glycol, $5 \mathrm{mM}$ dithiothreitol, and $1 \mathrm{mM}$ phenylmethylsulfonyl flouride (PMSF). The homogenate was centrifuged at 20,000 $\times$ $g$ for 20 min at $4^{\circ} \mathrm{C}$ to obtain the soluble protein.

\section{Enzyme assays and protein determination.}

GS activity was measured by the transferase assay (Ferguson and Sims 1974). One unit of activity represents $1 \mu$ mol of $\gamma$ glutamyl-hydroxamate formed per minute at $30^{\circ} \mathrm{C}$. NADHGOGAT and PEPc activities were assayed spectrophotometrically at $340 \mathrm{~nm}$ as described by Singh and Srivastava (1986) and by Deroche and associates (1983), respectively. SS was assayed by coupling the production of UDP-glucose to the reduction of nicotinamide adenine dinucleotide (NAD) in the presence of an excess of UDP-glucose dehydrogenase (Boehringer, Mannheim, Germany) and the change in $A_{340}$ followed as described by Morell and Copeland (1985). XDH activity was assayed by NAD+ reduction at $340 \mathrm{~nm}$ in a reaction mixture containing $50 \mathrm{mM}$ K-phosphate, $\mathrm{pH} 7.5,0.3 \mathrm{mM}$ NAD, and $0.1 \mathrm{mM}$ xanthine according to Reynolds and associates (1982). Uricase activity was detected spectrophotometrically following the reduction in absorbance of uric acid at $293 \mathrm{~nm}$ at $26^{\circ} \mathrm{C}$ (Christensen and Jochimsen 1983). The freshly prepared assay mixture contained $85 \mathrm{mM}$ glycine/ $\mathrm{NaOH}(\mathrm{pH} 10)$ and 50 $\mathrm{mM}$ uric acid per $\mathrm{ml}$. The reaction was started with the addition of the enzyme. G6PDH was assayed as described in Copeland and associates (1989). Glucose-6-phosphate was added to start the assay, and NADPH formation was followed at $340 \mathrm{~nm}$. AAT activity was measured as described in Gordon and Kessler (1990). The AAT activity in bean nodules did not change following incubation with pyridoxal phosphate. Therefore, this coenzyme was not included in any of the assays. Allantoinase activity was determined by measuring the enzymic formation of allantoic acid. Allantoic acid was measured as the diphenylformazan of glyoxylate, which absorbs strongly at $520 \mathrm{~nm}$, after degradation of allantoic acid by boiling in diluted $\mathrm{HCl}$ as described by Schubert (1981). Protein was measured by the method of Bradford (1976), using bovine serum albumin as standard. If not indicated otherwise, data are means of at least three independent experiments. Error bars indicate \pm standard error.

\section{Collection and analysis of xylem exudates.}

Xylem exudate was collected for $1 \mathrm{~h}$ (noon to 1:00 P.M.) from the cut stems of 10 to 15 plants, $1 \mathrm{~h}$ after the surrounding soil had been thoroughly watered. After recording the volume, pooled sap was stored at $-20^{\circ} \mathrm{C}$ for later analysis. The concentration of the ureides in the exudates was measured using the differential analysis of Vogels and Van Der Drift (1970). Amino acids were quantified fluorimetrically by using a precolumn derivation technique with 9-fluorenylmethyl chloroformate and a Nova-Pak $\mathrm{C}_{18}$ column as described by Cevallos and associates (1996).

\section{GS, PEPc, NADH-GOGAT, and SS probes.}

A GS cDNA clone of $1.4 \mathrm{~kb}$ from nodules of Lotus japonicus, kindly provided by Dr. Stougaard (Thykjaer et al. 1997), was used for Northern analysis.

Using alfalfa anti-PEPc antibodies and an alfalfa NADHGOGAT clone (kindly provided for Dr. Carroll Vance), two
PEPc (PvPEPc-2 and PvPEPc-5; accession numbers AF 314923 and AF 288382, respectively), a 2.2-kb 3' fragment of the nodule-enhanced PvPEPc-5 clone was used to compare the mRNA levels of PEPc between CE3- and CFN037-induced nodules. Two NADH-GOGAT (PvNADH-GOGAT-4 and PvNADH-GOGAT-15; accession numbers AF 314924 and AF 314925 , respectively) clones were isolated from a $\lambda$ Zap cDNA library, derived from 15-day-old bean nodules (data not shown). A 255-bp 3' UTR-specific fragment from PvNADHGOGAT-4 and a 282-bp 3' UTR-specific fragment from PvNADH-GOGAT-15 were amplified and used as probes. These two NADH-GOGAT-specific probes did not present cross hybridization. Based on the consensus sequences among SS of different plant species, 5'-dGCACAGTGCCTCCTGAAACC- $3^{\prime}$ was used as a consensus sense primer and $5^{\prime}$ dCTTGAGATCCACTTGCGAAC- $3^{\prime}$ as a consensus antisense primer. The nodule cDNA library mentioned above was subjected to polymerase chain reaction (PCR) with these two primers. Amplification was achieved in a DNA thermal cycler (MJ Research, Inc., Weltham, MA, U.S.A.) with the following conditions: 30 cycles of denaturation at $94^{\circ} \mathrm{C}$ for $1 \mathrm{~min}$, annealing at $50^{\circ} \mathrm{C}$ for $1.5 \mathrm{~min}$, and elongation at $72^{\circ} \mathrm{C}$ for $2 \mathrm{~min}$. Finally, the reaction mixture was kept at $72^{\circ} \mathrm{C}$ for $10 \mathrm{~min}$. The PCR products were checked on $1.5 \%$ agarose gels. The appropriate 500-bp fragment was purified using the Geneclean Kit (Stratagene, La Jolla, CA, U.S.A.) and used as probe.

\section{RNA isolation and Northern analysis.}

Total RNA was extracted from nodules harvested at different times from 11 to 21 days after inoculation. RNA was prepared according to the procedure of de Vries and associates (1988). RNA ( $20 \mu \mathrm{g})$ from each nodule-harvested sample was separated in a $1 \%$ (wt/vol) agarose gel containing $2.2 \mathrm{M}$ formaldehyde and transferred to Zeta Probe (Bio-Rad, Hercules, CA, U.S.A.) membranes by capillary blotting. The blots were probed with ${ }^{32} \mathrm{P}$-labeled PvNADH-GOGAT-4, PvNADHGOGAT-15, PvPEPc-5, SS, and GS probes, were washed with $2 \times \mathrm{SSC}(1 \times \mathrm{SSC}$ is $0.15 \mathrm{M} \mathrm{NaCl}$ plus $0.015 \mathrm{M}$ sodium citrate) and $0.1 \%(\mathrm{wt} / \mathrm{vol})$ sodium dodecyl sulfate at $50^{\circ} \mathrm{C}$ for GS (heterologous probe) and at $65^{\circ} \mathrm{C}$ for PEPc, SS, and NADHGOGAT, and were exposed to Kodak X-Omat film. To ensure that equal amounts of RNA were loaded, the gels were stained with ethidium bromide and photographed.

\section{ACKNOWLEDGMENTS}

This project was supported in part by a research grant (no.IN216696) from U.N.A.M. Dirección General de Asuntos del Personal Académico and in part by the Consejo Nacional de Ciencia y Tecnología (grant no. G31751-B). We thank M. Soberón for providing Rhizobium mutant CFN037, C. Vance for providing anti-NADH-GOGAT and anti-PEPc antibodies, G. Hernández for reviewing this manuscript, and A. Sánchez for technical support in the greenhouse.

\section{LITERATURE CITED}

Atkins, C. P. 1982. De novo purine synthesis in nitrogen-fixing nodules of cowpea (Vigna unguiculata L. Walp.) and Soybean (Glycine max L. Merr). Plant Physiol. 70:55-60.

Atkins, C. P., Storer, P. J., and Young, E. B. 1991. Translocation of nitrogen and expression of nodule-specific uricase (nodulin-35) in Robinia pseudoacacia. Physiol. Plant. 83:483-491.

Benny, A. G., and Boland, M. J. 1977. Enzymes of nitrogen metabolism in legume nodules. Purification and properties of NADH-dependent glutamate synthase from lupine nodules. Eur. J. Biochem. 79:355-362.

Bradford, M. M. 1976. A rapid and sensitive method for the quantification of micrograms quantities of protein utilizing the principle of proteindye binding. Anal. Biochem. 72:248-254.

Broughton, W. J., and Dilworth, M. J. 1971. Control of leghemoglobin synthesis in snake beans. Biochem. J. 125:1075-1080. 
Cevallos, M. A., Encarnación, S., Leija, A., Mora, Y., and Mora, J. 1996. Genetic and physiological characterization of a Rhizobium etli mutant strain unable to synthesize poly- $\beta$-hydroxybutyrate. J. Bacteriol. 178:1646-1654.

Chen, F. L., and Cullimore, J. V. 1988. Two isoforms of NADH-dependent glutamate synthase in root nodules of Phaseolus vulgaris L. Plant Physiol. 88:1411-1417.

Christensen, T. M. I. E., and Jochimsen, B. U. 1983. Enzymes of ureide synthesis in pea and soybean. Plant Physiol. 72:56-59.

Copeland, L., Vella J., and Hong, Z. 1989. Enzymes of carbohydrate metabolism in soybean nodules. Phytochemistry 28:57-61.

Deroche, M. E., and Carrayol, E. 1988. Nodule phosphoenolpyruvate carboxylase: A review. Physiol. Plant. 74:775-782.

Deroche, M. E., Carrayol, E., and Jolivet, E. 1983. Phosphoenolpyruvate carboxylase in legume nodules. Physiol. Vég. 21:1075-1081.

de Vries, S., Hoge, H., and Bisseling, T. 1988. Isolation of total polysomal RNA from plant tissues. Pages 1-3 in: Plant Molecular Biology Manual B6. Kluwer Academic Publishers, Dordrecht, The Netherlands.

Ferguson, A. R., and Sims, A. P. 1974. The regulation of glutamine metabolism in Candida utilis: The role of glutamine in the control of glutamine synthetase. J. Gen. Microbiol. 80:159-181.

Gordon, A. J., and Kessler, W. 1990. Defoliation-induced stress in nodules of white clover. 2. Immunological and enzymic measurements of key proteins. J. Exp. Bot. 41:1255-1262.

Gregerson, R. G., Miller, S. S., Twary, S. N., Gantt, J. S., and Vance, C. P. 1993. Molecular characterization of NADH-dependent glutamate synthase from alfalfa nodules. Plant Cell 5:215-226.

Griffith, S. M., and Vance, C. P. 1989. Aspartate aminotransferase in alfalfa root nodules. I. Purification and partial characterization. Plant Physiol. 90:1622-1629.

Herridge, D. F. 1982. Relative abundance of ureides and nitrate in plant tissues of soybean as a quantitative assay of nitrogen fixation. Plant Physiol. 70:1-6.

Hong, Z. Q., and Copeland, L. 1990. Pentose phosphate pathway enzymes in nitrogen-fixing leguminous root nodules. Phytochemistry 29:24372400 .

King, B. J., Layzell, D. B., and Canvin, D. T. 1986. The role of dark carbon dioxide fixation in root nodules of soybean. Plant Physiol. 81:200-205.

McClure, P. R., and Israel, D. W. 1979. Transport of nitrogen in the xylem of soybean plants. Plant Physiol. 64:411-416.

Miranda, J., Membrillo-Hernandez, M. L., Tabche, M. L., and Soberón, M. 1996. Rhizobium etli cytochrome mutants with derepressed expression of cytochrome terminal oxidases and enhanced symbiotic nitrogen accumulation. Appl. Microbiol. Biotechnol. 45:182-188.

Miranda, J., Morera, C., Taboada, H., Dávalos, A., Encarnación. S., Mora J., and Soberón. M. 1997. Expression of thiamin biosynthetic genes (thiCOGE) and production of symbiotic terminal oxidase $c b b_{3}$ in Rhizobium etli. J. Bacteriol. 179:6887-6893.

Morell, M., and Copeland, L. 1985. Sucrose synthase of soybean nodules. Plant Physiol. 78:149-154.
Noel, K. D., Sanchez, A., Fernandez, L., Leemans, J., and Cevallos, M. A. 1984. Rhizobium phaseoli symbiotic mutants with transposon Tn5 insertions. J. Bacteriol. 158:148-155.

Ortega, J. L., Sánchez, F., Soberón, M., and Lara, M. 1992. Regulation of nodule glutamine synthetase by $\mathrm{CO}_{2}$ levels in bean (Phaseolus vulgaris L.). Plant Physiol. 98:584-587.

Petersen, L. A., and Downs, D. M. 1997. Identification and characterization of an operon in Salmonella typhimurium involved in thiamine biosynthesis. J. Bacteriol. 179:4894-4900.

Ramírez, M., Valderrama, B., Arredondo-Peter, R., Soberón, M., Mora, J., and Hernández, G. 1999. Rhizobium etli genetically engineered for the heterologous expression of Vitreoscilla sp. hemoglobin: Effects on freeliving and symbiosis. Mol. Plant-Microbe Interact. 12:1008-1015.

Reynolds, P. H. S., Boland, M. J., Blevins, D. G., Schubert, K. R., and Randall, D. D. 1982. Enzymes of amide and ureide biogenesis in developing soybean nodules. Plant Physiol. 69:1334-1338.

Schubert, K. R. 1981. Enzymes of purine biosynthesis and catabolism in Glycine max. Plant Physiol. 68:1115-1122.

Schubert, K. R. 1986. Products of biological nitrogen fixation in higher plants: Synthesis, transport, and metabolism. Annu. Rev. Plant Physiol 37:537-574.

Singh, R. P., and Srivastava, H. H. 1986. Increase in glutamate synthase (NADH) activity in maize seedlings in response to nitrate and ammonium nitrogen. Physiol. Plant. 66:413-416.

Soberón, M., Membrillo-Hernandez, J., Aguilar, G. R., and Sánchez, F. 1990. Isolation of Rhizobium phaseoli Tn-5 induced mutants with altered expression of cytochrome terminal oxidases $o$ and $a a_{3}$. J. Bacteriol. 172:1676-1680.

Soberón, M., Williams, H. D., Poole, R. K., and Escamilla, E. 1989. Isolation of a Rhizobium phaseoli cytochrome mutant with enhanced respiration and symbiotic nitrogen fixation. J. Bacteriol. 171:465-472.

Tajima, S., and Kouchi, H. 1996. Metabolism and compartmentation of carbon and nitrogen in legume nodules. Pages 27-60 in: Plant-Microbe Interactions. G. Stacey and N. Keen, eds. Chapman \& Hall, New York.

Thykjaer, T., Danielsen, D., She, Q., and Stougaard, J. 1997. Organization and expression of genes in the genome region surrounding the glutamine synthetase gene Gln1 from Lotus japonicus. Mol. Gen. Genet. 255:628-636.

van Berkum, P., Sloger, C., Weber, D. F., Cregan, P. B., and Keyser, H. H 1985. Relationship between ureide $\mathrm{N}$ and $\mathrm{N}_{2}$ fixation, aboveground $\mathrm{N}$ accumulation, acetylene reduction, and nodule mass in greenhouse and field studies with Glycine max L. (Merr). Plant Physiol. 77:53-58.

Vogels, G. D., and Van Der Drift, C. 1970. Differential analyses of glyoxylate derivatives. Anal. Biochem. 33:143-157.

White, R. L., and Spenser, I. D. 1996. Biosynthesis of thiamine. In: Es cherichia coli and Salmonella typhimurium: Cellular and Molecular Biology, 2nd ed. F. C. Neidhardt, R. Curtis, III, J. L. Ingraham, E. C. C. Lin, K. B. Low, B. Magasanik, W. S. Reznikoff, M. Riley, M. Schaechter, and H. E. Umbarger, eds. American Society for Microbiology, Washington, D.C. 